\title{
On the Occurrence of Anhydrite in the Sulphatic Claystones of the Gypsum Keuper
}

\author{
G. Anagnostou $\cdot$ K. Serafeimidis $\cdot$ A. Vrakas
}

Received: 3 May 2013/Accepted: 25 February 2014/Published online: 15 March 2014

(C) Springer-Verlag Wien 2014

\begin{abstract}
We investigate why the sulphatic claystones of the Gypsum Keuper contain anhydrite rather than gypsum even at small depths of cover. This question is relevant due to the phenomenon of swelling of anhydritic claystones, which is attributed to the transformation of anhydrite into gypsum and has caused serious damage to a number of tunnels. In tunnelling, the Gypsum Keuper formation is crossed at rather small depths, where simplified thermodynamic considerations indicate that the calcium sulphate should be encountered in its hydrated form, i.e. as gypsum rather than as anhydrite. Understanding why anhydrite can be found at small depths is not only interesting from a fundamental point of view, but also necessary in order to formulate adequate initial conditions for the continuummechanical models that simulate the chemo-mechanical and transport processes in swelling anhydritic claystones. The paper quantitatively examines three reasons which, alone or in combination, might explain the occurrence of anhydrite: the small size of the pores in argillaceous rocks; locally high stresses in the vicinity of the sulphate crystals; and the thermodynamic state of the pore water. The computations of the paper take account of the results of porosimetry experiments on samples from two Swiss tunnels in Gypsum Keuper and show that the most probable reason is the thermodynamic state of the pore water, i.e. its ability to participate in chemical reactions. More specifically, the clay minerals reduce the chemical potential of the pore water, thus increasing the solubility of the gypsum and shifting the thermodynamic equilibrium in favour of anhydrite.
\end{abstract}

G. Anagnostou $(\varangle) \cdot$ K. Serafeimidis · A. Vrakas

ETH, Zurich, Switzerland

e-mail: georg.anagnostou@igt.baug.ethz.ch
Keywords Swelling · Tunnelling · Gypsum · Anhydrite · Keuper

\section{List of Symbols}

$b \quad$ Coefficient

$c_{e q, A} \quad$ Equilibrium concentration of anhydrite

$c_{e q, G} \quad$ Equilibrium concentration of gypsum

$c_{0} \quad$ Concentration at standard state

$F_{p} \quad$ Area of the pores

$F_{\text {tot }} \quad$ Total area

$g \quad$ Gravitational acceleration

$H \quad$ Depth of cover

$L \quad$ Side length

$n \quad$ Pore percentage

$n_{c r} \quad$ Critical pore percentage

$p_{A} \quad$ Anhydrite pressure

$p_{G} \quad$ Gypsum pressure

$p_{S 0} \quad$ Lithostatic pressure

$p_{W} \quad$ Pore water pressure

$p_{W 0} \quad$ Initial (in situ) pore water pressure

$p_{W 1} \quad$ Pore water pressure after swelling test

$p_{G, U L} \quad$ Upper limit of the gypsum pressure

$R \quad$ Universal gas constant

$r_{A} \quad$ Radius of anhydrite particles

$r_{c r} \quad$ Critical pore radius

$r_{G} \quad$ Radius of gypsum particles

$r_{p} \quad$ Pore radius

$T \quad$ Temperature

$T_{0} \quad$ Temperature at standard state

$V_{A}^{0} \quad$ Molar volume of anhydrite at standard state

$V_{G}^{0} \quad$ Molar volume of gypsum at standard state

$V_{W}^{0} \quad$ Molar volume of water at standard state

$V_{W} \quad$ Molar volume of water 


\section{Greek Symbols}

$a_{W} \quad$ Water activity

$\gamma_{A} \quad$ Surface free energy of the anhydrite-water interface

$\gamma_{G} \quad$ Surface free energy of the gypsum-water interface

$\gamma_{ \pm} \quad$ Mean activity coefficient

$\Delta_{r, G A} G^{0} \quad$ Standard Gibbs energy of anhydrite hydration

$\Delta_{r, G A} S^{0} \quad$ Standard entropy of anhydrite hydration

$\Delta_{r, A} V^{0} \quad$ Standard volume of anhydrite dissolution

$\Delta_{r, G} V^{0} \quad$ Standard volume of gypsum dissolution

$\sigma \quad$ Total stress

$\sigma_{0} \quad$ Initial total stress

$\sigma_{s} \quad$ Maximum swelling pressure

$\sigma^{\prime} \quad$ Effective stress

$\sigma_{0}^{\prime} \quad$ Initial (in situ) effective stress

$\rho_{R} \quad$ Rock density

$\rho_{W} \quad$ Water density

$\phi \quad$ Porosity

$\phi_{c r} \quad$ Critical porosity

$\Psi \quad$ Potential

$\Psi_{0} \quad$ Potential of pore water in situ

$\Psi_{1} \quad$ Potential of pore water after swelling test

\section{Introduction}

Rock swelling represents the most serious problem for tunnels through the Gypsum Keuper formation in northwestern Switzerland (Jura Mountains) and south-western Germany ( $c f$., for example, Amstad and Kovári 2001). The Gypsum Keuper consists of alternating sequences of sandstones, limestones, dolomites and claystones containing finely distributed anhydrite and gypsum. Swelling phenomena are observed only in the anhydritic claystones, which are encountered in tunnelling at depths of mostly $50-150 \mathrm{~m}$. The swelling is attributed to the combined effect of the anhydrite to gypsum transformation $\left(\mathrm{CaSO}_{4}+2 \mathrm{H}_{2} \mathrm{O} \rightarrow \mathrm{CaSO}_{4} \cdot 2 \mathrm{H}_{2} \mathrm{O}\right)$ and the water uptake by expansive clay minerals such as corrensite, which are also present in Gypsum Keuper (Lippmann 1976; Jordan 1994). The following brief description of the geology of the Gypsum Keuper is based mainly on Amstad and Kovári (2001).

The Gypsum Keuper in south-western Germany (BadenWürttemberg) can be divided into three zones (Fig. 1a). In the leached Gypsum Keuper, above the so-called "gypsum level", a big fraction of the sulphate has been dissolved and transported away. The leached Gypsum Keuper consisting of weathered rocks (marls and claystones) with gypsum residues therefore generally exhibits a high permeability and is water bearing. A transition zone separates the

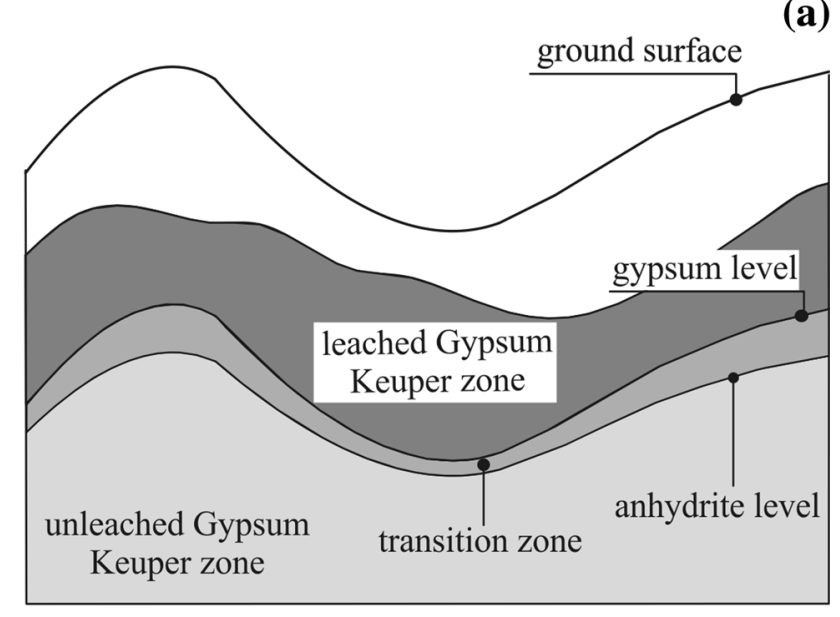

(b)

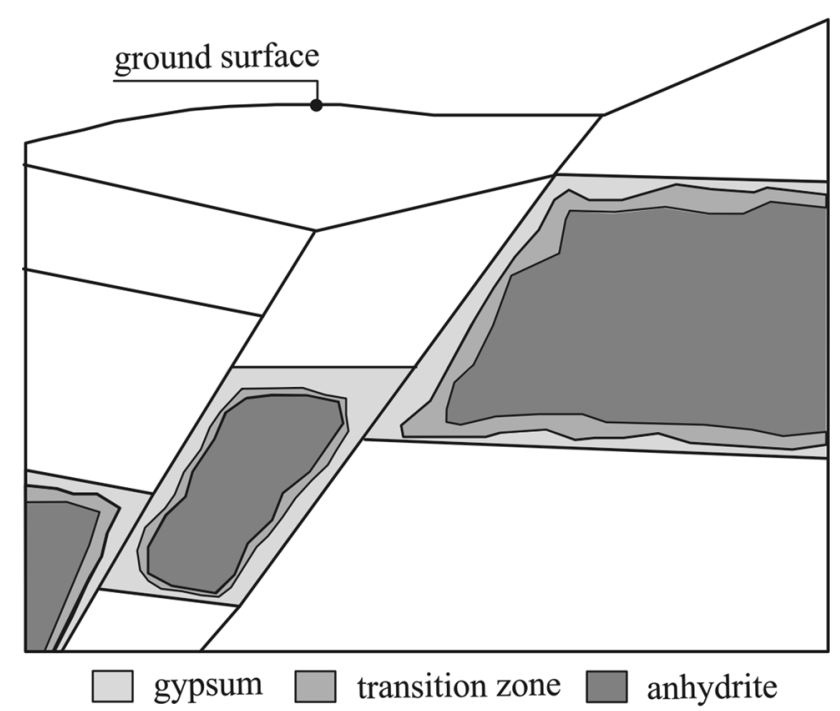

Fig. 1 Gypsum Keuper, $\mathbf{a}$ in Baden-Württemberg and $\mathbf{b}$ in tabular Jura (after Amstad and Kovári 2001)

leached from the unleached Gypsum Keuper. Due to the low permeability of the transition zone, little water flow is observed there. The "anhydrite level" represents the upper boundary of the zone, where calcium sulphate is present in its anhydrous form. In this zone, the rock permeability is very low and the seepage flow practically non-existent (Krause and Wurm 1975; Krause 1976; Kuhnhenn and Lorscheider 1979). It is interesting to note that the gypsum level and the anhydrite level approximately follow the morphology of the surface (Fig. 1a), exhibiting depressions beneath valleys or close to the tunnel portals (Krause and Wurm 1975; Krause 1976; Prommersberger and Kuhnhenn 1989; Paul and Wichter 1996).

In the Jura Mountains of Switzerland, the Gypsum Keuper is divided in that of the tabular Jura and of the 
folded Jura (Jordan 1994). The tabular Jura is characterised by the presence of faults creating the so-called Gypsum Keuper blocks (Fig. 1b). At the boundaries of these blocks across the fault zones, the sulphatic rock has been dissolved and subsequently transported away by the circulating water. Each Gypsum Keuper block in the tabular Jura is surrounded by a zone characterised by a variable degree of gypsification. The folded Jura is characterised by intense folding and overthrusting on the tabular Jura. In the course of these tectonic processes, anhydrite came into contact with water and partially transformed to gypsum, with the consequence that gypsum can be present at greater depths (Jordan 1994). Unlike the Gypsum Keuper formation of Baden-Württemberg, the anhydrite- and gypsum levels are not unique and do not follow the surface morphology closely.

These forms of Gypsum Keuper indicate the importance of water circulation for the gypsification process. The occurrence of anhydrite with the relatively small overburdens of the Keuper tunnels is surprising at first glance because one might expect gypsum rather than anhydrite to be the stable phase at the pressure and temperature conditions of these depths. Figure 2 shows the anhydritegypsum equilibrium temperature as a function of the depth under common simplifying assumptions. The actual depth and temperature values when tunnelling through Gypsum Keuper are clearly on the left of the equilibrium line (Fig. 2), which means that the calcium sulphate should be present as gypsum rather than as anhydrite.

The literature includes few works dealing with the presence of anhydrite at small depths, and these mainly focus on massive anhydrite beds. Rolnick (1954), for example, discussed the findings from drill holes in evaporitic deposits in Nova Scotia and attributed the occurrence of anhydrite to chemical kinetics (extremely slow hydration of the anhydrite). In the following, we examine the literature dealing specifically with the case of finely distributed anhydrite. The latter is different from massive anhydrite in that it offers a large specific surface to hydration.

Lippmann and Schüle (1975) introduced the so-called "corrensite-anhydrite theory", according to which the existence of anhydrite rather than gypsum in the rock provides an indication as to the thermodynamic characteristics of corrensite (see also Lippmann 1976). More specifically, corrensite cannot exist in its swollen, hydrated state, because this would imply the presence of free water, which would in turn lead to the gradual transformation of anhydrite into gypsum within a period of some years. The access of water (via the seepage flow that is triggered by tunnel excavation) has a twofold effect. It will cause both the swelling of corrensite and the transformation of the anhydrite into gypsum. Since the latter is a rather slow

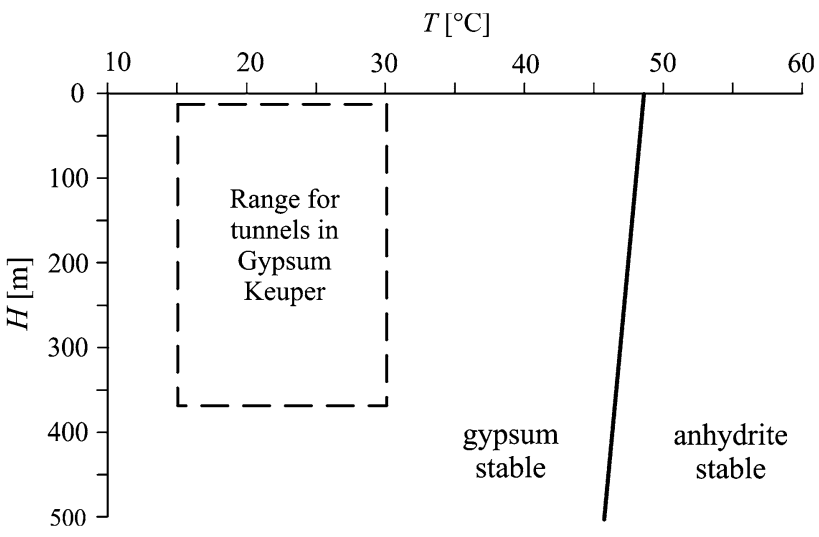

Fig. 2 Anhydrite-gypsum equilibrium diagram (computation after Serafeimidis and Anagnostou 2014 with: in situ solid pressure $p_{S 0}$ increasing linearly with depth $H$ by $25 \mathrm{kPa} / \mathrm{m}$; hydrostatic pore water pressure distribution $\left(p_{W}=0.40 p_{S 0}\right)$; water activity $\alpha_{W}=1$; no solid-liquid interfacial effects)

process, the swelling of corrensite constitutes the main initial swelling mechanism and thus the main cause of the heave of the tunnel invert at the early stage after tunnel excavation (Lippmann and Schüle 1975). Fecker (1981) provided support for the "corrensite-anhydrite theory" by performing in situ swelling tests, in which the invert of an exploratory gallery (in the Wagenburg tunnel near Stuttgart) was soaked with a saturated magnesium chloride solution. The dissolved magnesium chloride shifts the thermodynamic equilibrium in favour of anhydrite, i.e. it hinders the transformation of anhydrite to gypsum. Nevertheless, despite the suppression of the anhydrite transformation, considerable heave of the invert took place. According to Fecker (1981), this can only be attributed to the swelling of corrensite, thus proving the validity of the theory.

An interesting alternative hypothesis was put forward by Wichter (1989). He proposed that gypsum grows, starting from existing — and possibly very small—cavities, thereby compressing the surrounding rock and retarding or stopping the transformation process. The question therefore arises as to whether the stresses developing during growth might shift the equilibrium in favour of anhydrite, thus explaining the fact that anhydrite occurs at small depths.

Hauber et al. (2005) also commented on the fact that anhydrite has been found at small depths during tunnel excavations in Gypsum Keuper. The point is made that, even when assuming a high amount of dissolved salts in the circulating water (and thus low water activity, favouring thermodynamically stable anhydrite), the stability limit of anhydrite in terms of pressure and temperature is much higher than the actual values prevailing at the depths of the tunnels. They concluded that anhydrite should therefore actually be unstable at small depths. 
These studies, even though based upon qualitative considerations, provide useful indications as to the possible reasons for the occurrence of anhydrite at relatively shallow depths. The present paper aims to close existing knowledge gaps by investigating a number of hypotheses on this phenomenon quantitatively.

One possible scenario is that gypsum is indeed the thermodynamically stable phase (as indicated by Fig. 2), but is not present in situ either because of lack of water or because the hydration of anhydrite is an on-going process, which proceeds extremely slowly in geological times. This scenario does not, however, seem probable: On the one hand, anhydrite occurs in the form of veins or particles which are finely distributed in claystones of a very low porosity $(5-10 \%)$ but which are nevertheless saturated. On the other hand, the hydration of finely distributed anhydrite (in contrast to that of massive anhydrite beds) occurs rapidly due to its big specific surface. It may take months or years (depending on the specific surface areas of the mineral particles), but certainly not geologic time periods (Grob 1972; Pimentel 2007; Rauh 2009; Oldecop and Alonso 2012; Serafeimidis and Anagnostou 2013a).

For these reasons, we focus here on the alternative scenario that anhydrite is the thermodynamically stable phase. This would mean that one or more of the simplifying assumptions behind the thermodynamic equilibrium diagram of Fig. 2, which implies that gypsum rather than anhydrite is the stable form, must be false. Therefore, we examine which deviations from the assumptions of Fig. 2 might explain why anhydrite is the stable phase. Specifically, we pay attention to the assumptions concerning pore size, solid pressure and water activity, because a small pore size, high solid pressure and a low water activity shift the thermodynamic equilibrium in favour of anhydrite (Serafeimidis and Anagnostou 2014). The underlying ideas are:

- The pore size may be extremely small (in the range of a few $\mathrm{nm}$ ) with the consequence that solid-liquid interface effects become relevant, considerably increasing the chemical potential of gypsum.

- The growth of gypsum crystals may increase the stresses locally to values that are much higher than the ones corresponding to the overburden of the tunnels in Gypsum Keuper. (This hypothesis takes up Wichter's 1989 idea.)

- The activity of the pore water may be considerably lower than 1 due to its interactions with the clay minerals. (This hypothesis is very close to that of Lippmann and Schüle's 1975 as it also focuses on the thermodynamic state of the water.)

These three hypotheses, herein referred to as the "smallpore hypothesis", the "high-pressure hypothesis" and the "low water activity hypothesis", will be examined in Sects.
2, 3 and 4, respectively, making frequent use of the equations derived by Serafeimidis and Anagnostou (2014) for the equilibrium concentrations of anhydrite and gypsum (see Appendix). All equations adopt the geomechanics sign convention, according to which compressive stresses are positive.

The investigations made in the present paper indicate that the third hypothesis is the most probable one. The results of the paper, besides providing insight into an interesting observation, are also valuable for future research, as they assist in the formulation of adequate initial conditions for continuum-mechanical models of the chemo-mechanical and transport processes in swelling anhydritic claystones.

\section{The Small-Pore Hypothesis}

Small pores favour anhydrite as the stable phase, while large pores favour gypsum-all other conditions (pressure, temperature and water activity) being equal (Serafeimidis and Anagnostou 2014). This is due to the effect of surface energy, which is equivalent to that of a confining pressure. (The surface can be conceived as a stretched membrane that encloses the crystal and exerts a confining pressure upon it.)

Figure 3 shows, for given pressure and temperature conditions, the equilibrium concentration of gypsum as a function of the pore radius (solid line, computed with Eq. 6). With increasing pore radius, the surface energy and thus also the equilibrium concentration of gypsum decrease. Additionally, the diagram shows the equilibrium concentration of the anhydrite (dashed line, computed with

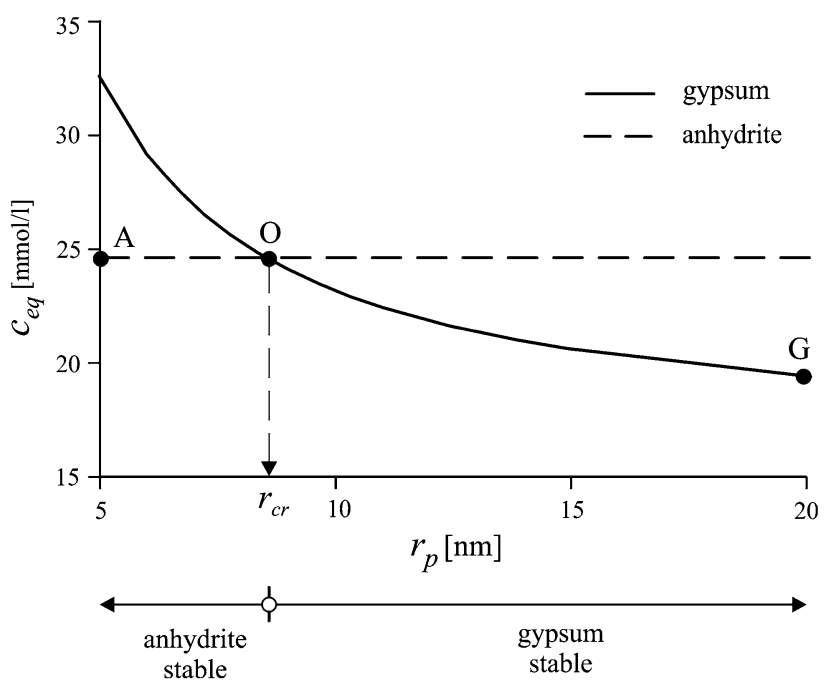

Fig. 3 Equilibrium concentration of anhydrite and gypsum as a function of the pore radius (water activity $\alpha_{W}=1$, temperature and pore pressure conditions of the Belchen tunnel, see bottom of Table 1) 
Eq. 7). In the pores with small radii $r_{p}$ (hereafter referred to as "subcritical pores"), anhydrite exhibits a lower equilibrium concentration than gypsum and therefore represents the thermodynamically stable phase. In the pores with great radii $r_{p}$ (hereafter referred to as "supercritical pores"), the opposite applies. The threshold pore size, i.e. the pore size where anhydrite and gypsum exhibit the same equilibrium concentration (intersection point $\mathrm{O}$ of the two lines), will be denoted hereinafter as the critical pore radius $r_{c r}$. This can be calculated on the basis of Eqs. (6) and (7) by setting the equilibrium concentrations of anhydrite and gypsum equal to each other and considering that the radius of the gypsum particles corresponds to the critical pore radius $\left(r_{G}=r_{c r}\right)$ :

$r_{c r}=\frac{2 \gamma_{G} V_{G}^{0}}{2 R T \ln a_{W}+\left(T-T_{0}\right) \Delta_{r, G A} S^{0}-\Delta_{r, G A} G^{0}+2 V_{W}^{0} p_{W}-p_{S 0}\left(V_{G}^{0}-V_{A}^{0}\right)}$

where $T, p_{S 0}$ and $p_{W}$ denote temperature, lithostatic pressure and pore water pressure, respectively (see Appendix for the meaning of the other symbols). In order to find out whether the actual pore sizes are bigger or smaller than the critical pore radius in the present case, the porosity and the pore size distribution of natural rock samples were determined by means of mercury intrusion porosimetry (MIP, $c f$. Abell et al. 1999) in the Clay Mineralogy Lab of our Institute (Röthlisberger 2012) and in the Swiss Federal Laboratories for Materials Testing and Research (Leemann and Wyrzykowski 2012). The samples were taken from the
Chienberg and the Belchen tunnel at depths of 50-55 and $200 \mathrm{~m}$, respectively. These tunnels are located in the Gypsum Keuper formation and have experienced serious damage due to swelling since and even during excavation (Grob 1972; Chiaverio and Thut 2010). A total of four tests were conducted on samples from the Chienberg tunnel (one by EMPA and three by the Clay Mineralogy Lab) and three tests on samples from the Belchen tunnel (one by EMPA and two by the Clay Mineralogy Lab). Anhydritic claystones consist of different constituents and may be very heterogeneous in the scale of a specimen. In order to determine the pore size distribution of the claystone matrix, samples with a macroscopically high content of clay were selected. The mass of the samples was $1.6-5.1$ gr.

Figure 4 shows the experimentally determined pore percentage $n$ as a function of the pore radius $r_{p}$ for the seven porosimetry tests. (For example, a percentage of $n=20 \%$ for a pore radius of $100 \mathrm{~nm}$ means that $20 \%$ of the total pore volume consists of pores with radius greater than $100 \mathrm{~nm}$.) The samples from the Belchen tunnel (solid lines) have smaller pores than the samples from the Chienberg tunnel (dashed lines), probably due to the greater depth of sampling ( 200 vs. $50 \mathrm{~m}$ ).

If the pressures at the sampling depths and the geothermal gradient in Northern Switzerland are taken into account, Eq. (1) leads to critical radii $r_{c r}$ between 7 and $40 \mathrm{~nm}$ depending on the pore water activity $\alpha_{W}$ (Table 1 , Column 3). These critical radii are also shown in Fig. 4

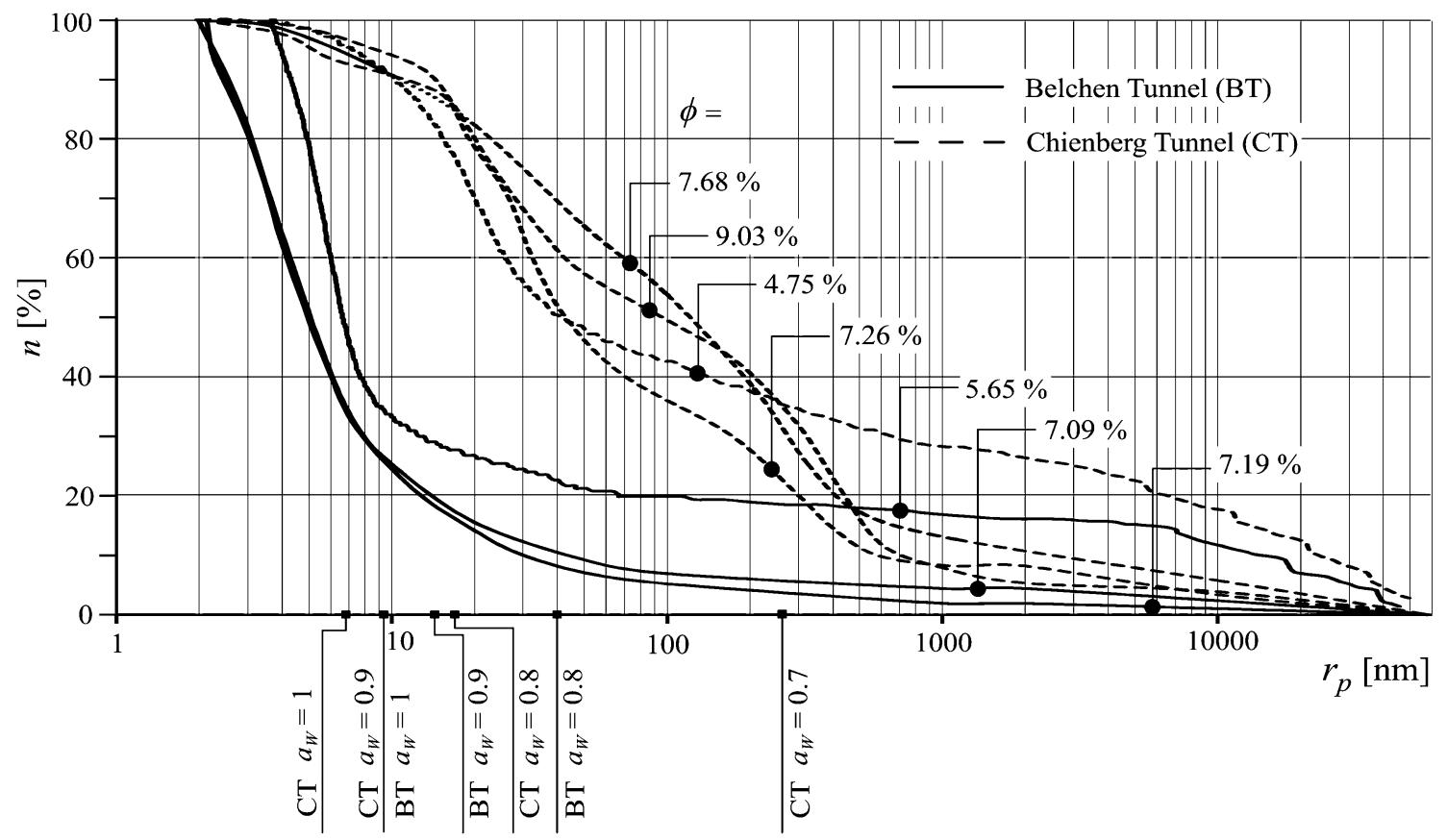

Fig. 4 Pore size distributions and porosities $\phi$ of samples from the Chienberg and the Belchen tunnel as well as critical radii $r_{c r}$ calculated at different water activities 
Table 1 Critical pore size $r_{c r}$, critical porosity $\phi_{c r}$ and upper limit $p_{G, U L}$ of the gypsum pressure

\begin{tabular}{lllll}
\hline 1 & 2 & 3 & 4 & 5 \\
& $\alpha_{W}$ & $r_{c r}(\mathrm{~nm})$ & $\phi_{c r}(\%)$ & $p_{G, U L}(\mathrm{MPa})$ \\
\hline $\mathrm{CT}^{\mathrm{a}}$ & 0.8 & 17 & $3.6-7.7$ & $4-6$ \\
& 0.9 & 9 & $4.3-8.5$ & $4-6$ \\
& 1.0 & 7 & $4.6-8.7$ & $4-5$ \\
$\mathrm{BT}^{\mathrm{b}}$ & 0.8 & 40 & $0.6-1.5$ & $43-75$ \\
& 0.9 & 14 & $1.4-1.9$ & $37-45$ \\
& 1.0 & 9 & $2.1-2.4$ & $32-35$ \\
\hline
\end{tabular}

a Chienberg tunnel $(H=50 \mathrm{~m}): T=15^{\circ} \mathrm{C}, p_{W}=0.5 \mathrm{MPa}, p_{S 0}=$ $1.25 \mathrm{MPa}$

b Belchen tunnel $(H=200 \mathrm{~m}): T=21^{\circ} \mathrm{C}, p_{W}=2 \mathrm{MPa}, p_{S 0}=$ $5 \mathrm{MPa}$

(beneath the abscissa). All of the samples clearly contain a larger (Chienberg tunnel) or smaller (Belchen tunnel) quantity of supercritical pores. The volume fraction of supercritical pores (hereafter referred to as the "supercritical porosity" $\phi_{c r}$ ) can be determined from the porosimetry curves of Fig. $4\left(\phi_{c r}=\phi_{n_{c r}}\right.$, where $n_{c r}$ denotes the pore percentage that corresponds to the critical radius $r_{c r}$ ) and is given in Table 1, Column 4.

As explained in the following, the presence of even a few supercritical pores is sufficient for the entire anhydrite to transform into gypsum-including the anhydrite in regions with small pores, where it represents the thermodynamically stable phase; the consequence ought to be a completely anhydrite-free rock. Assume that the rock contains both subcritical and supercritical pores. In the subcritical pores, where anhydrite represents the thermodynamically stable phase, the concentration $c$ in the pore water would be equal to the equilibrium concentration $c_{e q, A}$ of the anhydrite (given by the line $\mathrm{AO}$ in Fig. 3). Analogously, in the supercritical pores, the concentration would be equal to the equilibrium concentration $c_{e q, G}$ of gypsum (given by the line OG in Fig. 3). Such a non-uniform concentration field would be unstable: As the porosity of the claystones is interconnected, ions will migrate by diffusion from the subcritical pores to the supercritical pores, thus reducing the concentration in the former and increasing the concentration in the latter. This will trigger dissolution of anhydrite in the subcritical pores and gypsum growth in the supercritical pores. This process-mineral dissolution in the small pores, diffusion of the dissolved ions to the larger pores and crystal growth in the latter-will continue until all of the anhydrite is transformed. Such processes are well known in the literature (Flatt 2002; Scherer 2002, 2004).

In conclusion, the small-pore hypothesis must be abandoned even in the case of the extremely fine-porous claystones from the Belchen tunnel and even under the favourable assumptions of spherical pore shape and of negligible "ink-bottle" effect ( $c f$. Abell et al. 1999), which underestimate the supercritical porosity. (The effect of surface energy is more pronounced with spherical pores than with other shapes, for example, cylindrical pores. The "inkbottle" effect underestimates the percentage of large pores.)

\section{The High-Pressure Hypothesis}

As shown in the last section, the claystones of the Gypsum Keuper contain a smaller or larger quantity of supercritical pores where gypsum growth should occur. As the growth is partially constrained by the surrounding matrix, the gypsum will start to exert an increasing pressure upon the pore walls. Reciprocally (actio-reactio), the gypsum crystals will be subject to a gradually increasing pressure. Since a crystal under pressure has a higher solubility than a free crystal, the equilibrium concentration of the gypsum will increase during the constrained growth process. Consequently, the question arises as to whether the locally increased pressure might become so high that the equilibrium concentration of gypsum becomes equal to the ion concentration in the pore solution, i.e. equal to the equilibrium concentration of anhydrite. In this case, thermodynamic equilibrium would be established and the gypsum growth process would stop.

The development of a high stress locally around the growing gypsum is a necessary (but not a sufficient) condition for the high-pressure theory to be valid. Another necessary condition is that the formation of only a small amount of gypsum is sufficient to mobilise the required counterpressure in the surrounding matrix; were this not the case, a considerable quantity of gypsum would also be present in situ. A third necessary condition is that the radial stress that must develop at the pore wall in order for gypsum growth to stop is not high enough to cause tensile failure in an extended zone of the rock matrix between the supercritical pores; were this not the case, the rock at the scale of specimen would appear completely disintegrated, resembling granular soil, which does not agree with the observed quality of the anhydritic claystones. In the following, we investigate the first condition and show that it is rather improbable that the stress developing locally around the gypsum might stop the growth. As the high-pressure hypothesis fails to pass this first test, we can refrain from discussing the other two conditions here; it may be noted, however, that, according to a quantitative estimation not presented here, these conditions are not critical.

The stiffness and strength of the claystone matrix impose a limit on the stress developing during crystal growth; this limit also depends on the spatial distribution of the supercritical pores. An upper limit of the possible gypsum pressure $p_{G, U L}$ can be obtained by considering a claystone layer with sparsely distributed supercritical pores 

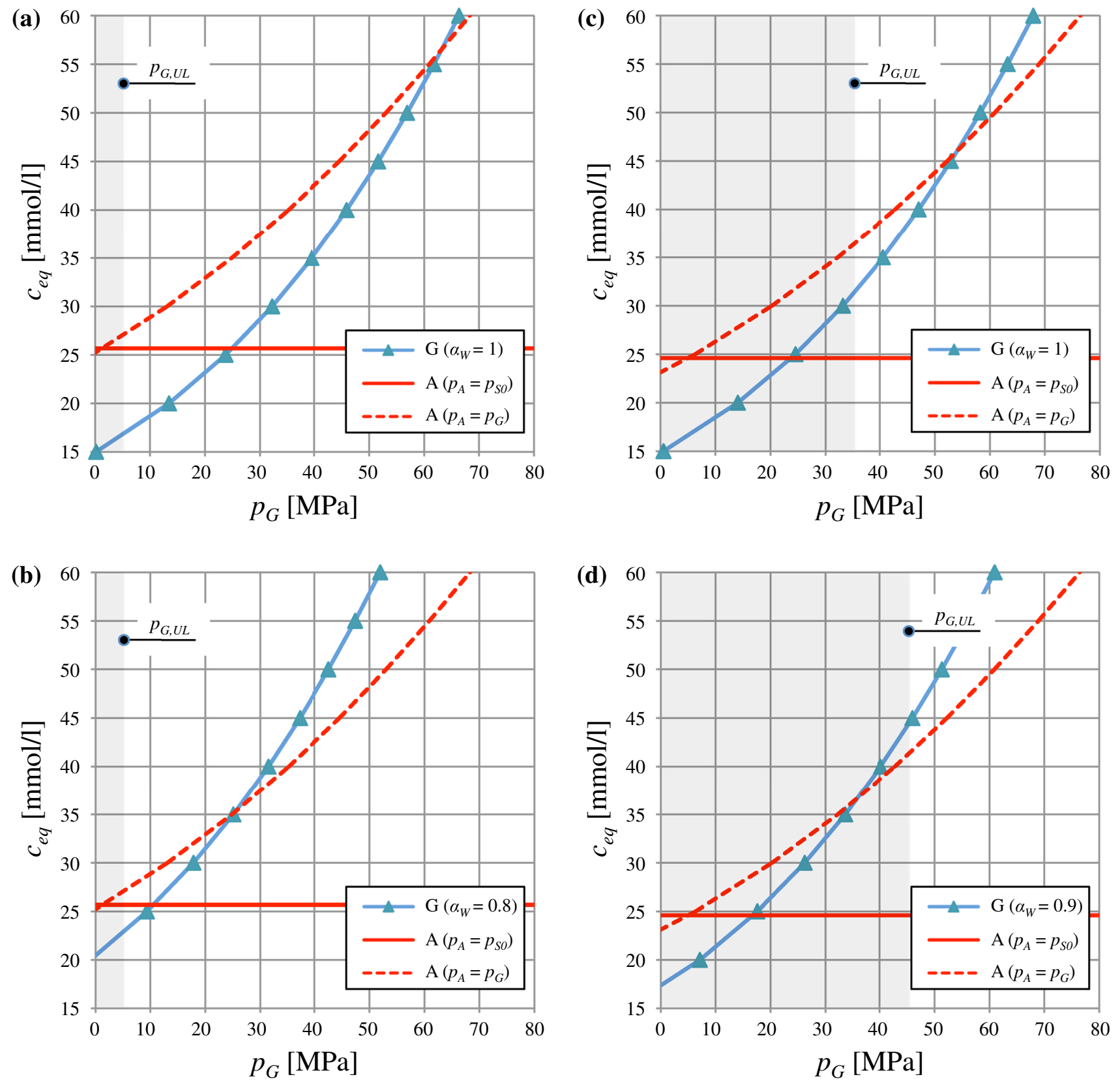

Fig. 5 Equilibrium concentration of anhydrite and gypsum as a function of the gypsum pressure $p_{G}\left(\gamma_{G} / r_{G} \cong \gamma_{A} / r_{A} \cong 0 ; p_{W}, p_{S 0}\right.$ and $T$ : see Table 1): a Chienberg tunnel for $\alpha_{W}=1$; b Chienberg tunnel for $\alpha_{W}=0.8$; $\mathbf{c}$ Belchen tunnel for $\alpha_{W}=1$; $\mathbf{d}$ Belchen tunnel for $\alpha_{W}=0.9$

at depth $H$ below the ground surface and formulating the equilibrium in the vertical direction for the theoretical borderline case, where the entire rock between the supercritical pores has failed in tension:

$p_{G, U L}=\frac{p_{S 0}-p_{W}}{F_{p} / F_{\text {tot }}}+p_{W}$,

where $F_{P} / F_{\text {tot }}$ is the fraction area of the supercritical pores in the horizontal cross-section, which can be taken equal to the volume fraction $\phi_{c r}$. It should be noted that Eq. (2) gives an average value for supercritical pores over the area $F_{p}$. The presence of an average value introduces an uncertainty, because it does not take account of variations in the stress among the pores. (Even if the average stress is high, the stress in some pores may be too low to stop gypsum growth.) Therefore, we will consider a more conservative model assuming a uniform pore size and a regular pore distribution on a cubic grid. In this case, the area fraction of the pores in a cross-section containing the equator planes of the pores reads as follows: 
$F_{p} / F_{t o t}=\frac{\pi}{4}\left(\frac{6 \phi_{c r}}{\pi}\right)^{2 / 3}=1.21 \phi_{c r}^{2 / 3}>\phi_{c r}$.

This model too presents an uncertainty in that it considers only an average pressure, but it is more conservative than taking the area fraction equal to $\varphi_{c r}$ because it leads to a smaller value for the upper limit $p_{G, U L}$. Column 5 of Table 1 gives the range of values for the upper limit $p_{G, U L}$ according to Eq. (2) with the area fraction according to Eq. (3): the gypsum pressure cannot be higher than 4-6 MPa in the case of Chienberg tunnel, but can reach 32-75 MPa in the case of Belchen tunnel due to the greater depth of cover and to the higher percentage of fine pores.

In the following, we investigate whether these pressures are able to shift the thermodynamic equilibrium in favour of anhydrite in the largest supercritical pores, where (on account of their size, which, according to Fig. 4 , is $>1 \mu \mathrm{m}$ ) the solid-liquid interfacial effects disappear. For this purpose, we check whether the equilibrium concentration of gypsum (Eq. 6) may reach that of anhydrite (Eq. 7).

Let us first consider the case of Chienberg tunnel. Figure $5 \mathrm{a}$ shows the equilibrium concentrations of gypsum and anhydrite as a function of the gypsum pressure $p_{G}$ assuming a water activity of 1 . The two lines given for the anhydrite bound the possible range of its equilibrium concentration: as the gypsum compresses the surrounding matrix, the anhydrite will experience a certain pressure increase; its pressure will be somewhere between the lithostatic pressure $p_{S 0}$ and the gypsum pressure $p_{G}$. The horizontal line of the diagram assumes that the anhydrite pressure remains equal to the lithostatic pressure $p_{S 0}$; the other line assumes that the anhydrite pressure is equal to that of gypsum. For gypsum pressures $p_{G}<p_{G, U L}(=5 \mathrm{MPa}$ according to Table 1, hatched area in Fig. 5a) the equilibrium concentration of anhydrite is higher than that of gypsum, which means that gypsum is the stable phase. This remains true even if a low water activity $\alpha_{W}$ of 0.80 is considered (Fig. 5b). Consequently, the high-pressure hypothesis surely fails to explain the presence of anhydrite in the case of the Chienberg tunnel.

Figure 5c, d applies to the case of Belchen tunnel and a water activity $\alpha_{W}$ of 1 or 0.9 , respectively. The larger overburden in combination with the relatively small area fraction of the supercritical pores allows the gypsum to develop a local pressure of up to 35-45 MPa. In this pressure range, the equilibrium concentration of gypsum might reach the equilibrium concentration of anhydrite, which means that the high-pressure hypothesis (alone or in combination with a moderate water activity) would fully explain the presence of anhydrite in situ.

However, as mentioned above, Eq. (2) does not take into account pressure variations among the pores, because the
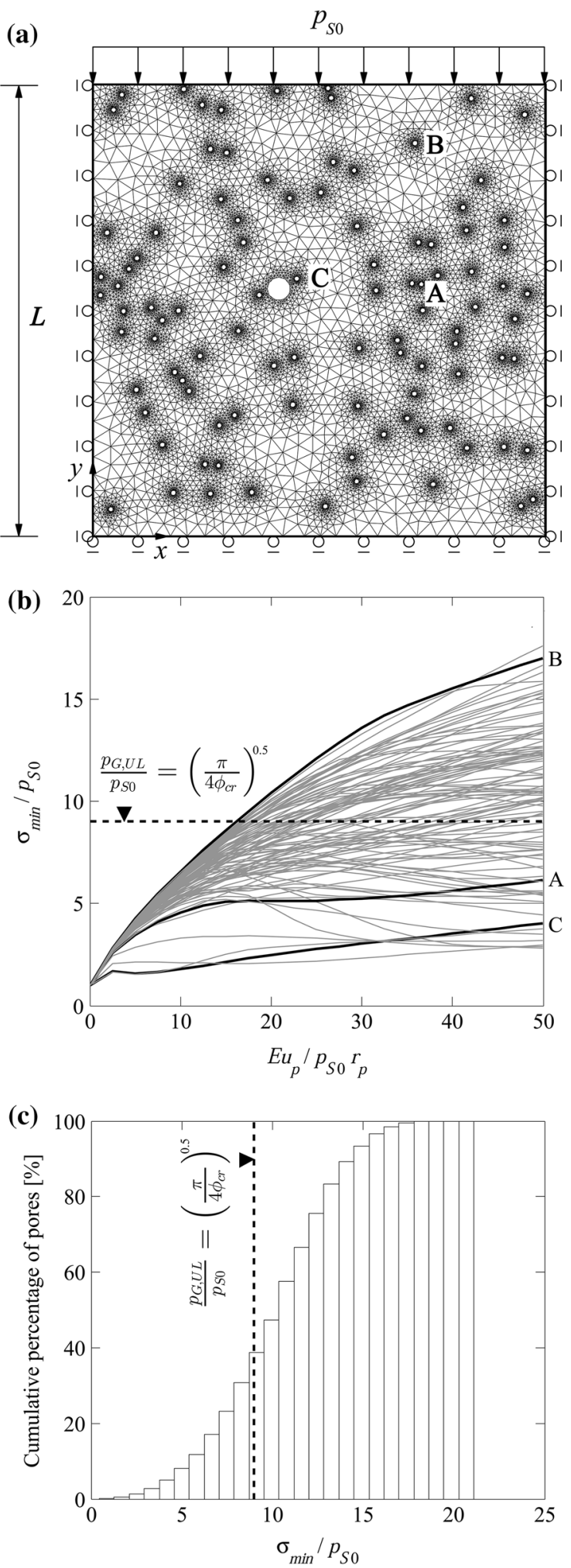

Fig. 6 a Boundary conditions and finite element mesh for a specific spatial arrangement of the pores; $\mathbf{b}$ normalised minimum principal stress as a function of the normalised cavity expansion; c cumulative distribution of the minimum principal stress at an expansion of $E u_{p} / p_{S 0} r_{p}=50$ (100 simulations, $10^{\prime} 100$ pores $)$ 
condition of static equilibrium in the vertical direction provides an upper limit only for the average pressure. In the following, we will show by means of a simple numerical example that the pressure scatter among the pores can be significant if the latter are randomly distributed and have different sizes. For simplicity (and without loss of generality in the results), we assume that the pore water pressure is atmospheric and that the pores are parallel, horizontal and cylindrical. These assumptions allow for a two-dimensional, purely mechanical stress analysis under plane strain conditions. The system under consideration consists of a cubic rock element of edge length $L$ containing 100 small supercritical pores (radius $L / 200$ ) and 1 bigger pore (radius $L / 40$ ); these assumptions lead to a porosity of about $1 \%$. Linearly elastic no-tension material behaviour is assumed. The initial stress field is taken to be uniform and isotropic according to the lithostatic pressure $p_{S 0}$. Figure $6 \mathrm{a}$ shows the boundary conditions. The numerical solution was carried out using the Abaqus finite element code (Dassault Systémes 2011).

Figure $6 \mathrm{~b}$ shows (for the system of Fig. 6a) the minimum principal stress $\sigma_{\min }$ of every pore as a function of its expansion, making use of the normalisation after Anagnostou and Kovári (1993). After some expansion, the stresses practically reach a plateau. The plateaus are on the average close to the upper pressure limit $p_{G, U L}$ resulting from the equilibrium condition in the vertical direction (dashed straight line), but exhibit a considerable scatter: some pores develop lower than average stresses because they form clusters (e.g. pore A, Fig. 6a); single, isolated pores are able to develop higher stresses (e.g. pore B); and small pores close to larger ones (e.g. pore C) cannot develop a high stress because the stress field in their vicinity is governed by the expansion of the larger pore, which reduces stresses in its tangential direction.

We analysed 100 randomly generated models in this way, containing 10,100 pores in total. Figure $6 \mathrm{c}$ shows the cumulative distribution of the minimum principal stress at a normalised expansion of 50. The average value is close to the analytically computed upper limit $p_{G, U L}$, but a considerable number of pores have significantly lower stress, and gypsum may be the stable phase here. The presence of even a few such pores would be sufficient for the whole anhydrite to transform into gypsum (basically for the same reasons as in Sect. 2, i.e. via ion diffusion from the subcritical pores towards the pores with an insufficiently high local stress).

The example discussed above at least calls into question the high-pressure hypothesis: The hypothesis would explain the presence of anhydrite at small depths only for extremely fine-porous anhydritic rocks, and only under the unrealistic assumption of poorly graded and uniformly distributed pores.

\section{The Low Water Activity Hypothesis}

As mentioned in the Introduction, low water activity increases the solubility of gypsum, thus shifting the thermodynamic equilibrium in favour of anhydrite. In order to estimate the water activity values at which anhydrite would represent the stable mineral, we set the equilibrium concentrations of gypsum and anhydrite given by Eqs. (6) and (7) equal to each other. Neglecting the effect of the solid-liquid interface energy, the water activity at which anhydrite and gypsum coexist in a system reads as follows:

$$
\begin{aligned}
& a_{W} \\
& =\exp \left(\frac{\Delta_{r, G A} G^{0}-\left(T-T_{0}\right) \Delta_{r, G A} S^{0}+\left(V_{G}^{0}-V_{A}^{0}\right) p_{S 0}-2 V_{W}^{0} p_{W}}{2 R T}\right) .
\end{aligned}
$$

Anhydrite is stable if the water activity is lower than the one given by Eq. (4). Figure 7 shows the equilibrium water activity as a function of the temperature for two depths of cover $(H=50$ and $300 \mathrm{~m})$, assuming that the lithostatic pressure $p_{S 0}$ and the pore water pressure $p_{W}$ increase linearly with the depth $H$ (i.e. $p_{S 0}=\rho_{R} g H$, $p_{W}=\rho_{W} g H$, where $g \cong 10 \mathrm{~m} / \mathrm{s}^{2}, \rho_{R}=2.5 \mathrm{~g} / \mathrm{cm}^{3}$ and $\rho_{W}=1 \mathrm{~g} / \mathrm{cm}^{3}$ denote the gravity acceleration, the rock mass density and the water density, respectively). In the relevant temperature range, the equilibrium water activity is $0.69-0.84$. Such low water activities might occur either as a consequence of high levels of dissolved ions in the pore water or due to the interaction between the pore water and the clay minerals. Mineralogical analyses of water from the Gypsum Keuper show, however, that the actual ionic concentration is far lower than the concentrations which would explain water activities as low as 0.70-0.80 ( $c f$. Serafeimidis and Anagnostou 2014). The remainder of the present section therefore deals with the second hypothesis. As discussed below, this scenario is entirely possible.

Taking into account the fact that the activity of the pore water is associated with its potential $\Psi\left(\alpha_{W}=\exp \left(\Psi V_{W} /\right.\right.$ $R T$ ), $c f$., e.g., Scanlon et al. 2002), Eq. (4) leads to the following expression for the potential at the anhydritegypsum equilibrium:

$$
\Psi=\frac{\Delta_{r, G A} G^{0}-\left(T-T_{0}\right) \Delta_{r, G A} S^{0}+\left(V_{G}^{0}-V_{A}^{0}\right) p_{S 0}}{2 V_{W}^{0}}-p_{W} .
$$

According to this equation, the equilibrium potential $\Psi$ varies between -50 and $-25 \mathrm{MPa}$ in the relevant depth and temperature range. Anhydrite would be stable under the conditions prevailing before tunnel excavation, provided the in situ pore water potential $\Psi_{0}$ is lower than the 


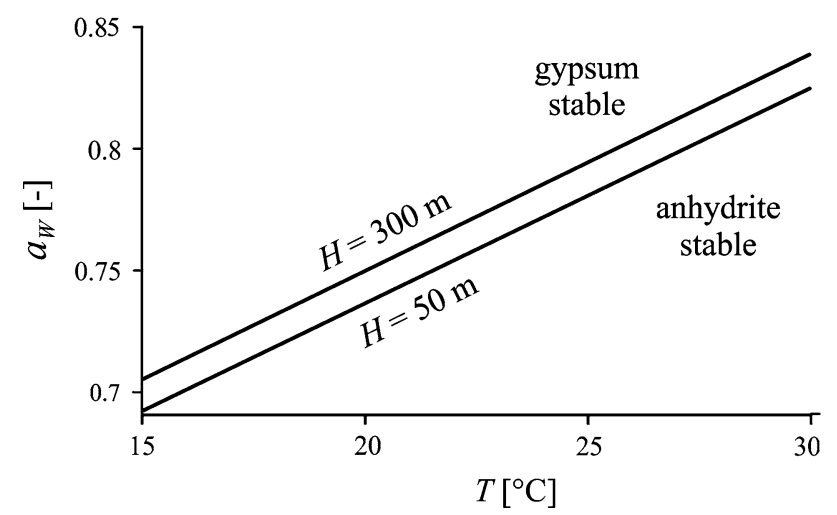

Fig. 7 Equilibrium activity of water as a function of the temperature at depths of 50 and $300 \mathrm{~m}$

equilibrium potential, i.e. -50 to $-25 \mathrm{MPa}$. It is well known from the literature that pore water in claystones often exhibits potentials as low as these, or very low activity values. Alonso and Olivella (2008), for example, measured potential values as low as -40 to $-20 \mathrm{MPa}$ by means of a transistor psychrometer ( $c f$. Woodburn et al. 1993). Other studies supporting the hypothesis of very low water potential or activity values include those of Mitaritonna et al. (2009), Mohajerani et al. (2012) and Zhang et al. (2012).

At this point, we would like to discuss a potential objection to the low pore water potential argument. The case might be made that such high negative values of the water potential imply unrealistically high swelling pressures in the claystones: As shown by Anagnostou (1993), based upon Terzaghi's principle of effective stress in its classic form $\left(\sigma^{\prime}=\sigma-\left(\Psi+p_{W}\right)\right)$, the maximum swelling pressure $\sigma_{s}$, i.e. the pressure developing in a laboratory test while preventing the development of swelling strain (a socalled "swelling pressure test" after ISRM 1999), is equal to the in situ effective stress $\sigma_{0}^{\prime}$, i.e. $\sigma_{s}=\sigma_{0}-$ $\left(\Psi_{0}+p_{W 0}\right)$, where $\sigma_{0}$ and $\left(\Psi_{0}+p_{W 0}\right)$ denote the in situ total stress and the in situ total pore water potential, respectively; therefore, an in situ pore water potential $\Psi_{0}$ of -25 to $-50 \mathrm{MPa}$ would lead to a swelling pressure of more than $25 \mathrm{MPa}$, which is much higher than the measured swelling pressures of claystones (typically 1-3 MPa, $c f$. Anagnostou 1991). This might then be taken to indicate that the low water activity assumption is wrong.

The argument outlined above is not, however, correct. In the following, we will see that the measured swelling pressures $\sigma_{s}$ can certainly be lower than the value corresponding to the in situ pore water potential $-\Psi_{0}$. In order to explain this, let us consider how swelling strain develops when the water activity increases from extremely low values to 1 . Figure 8 is based upon Mering (1946), who investigated the swelling of montmorillonite over the entire intracrystalline and osmotic range, and shows swelling

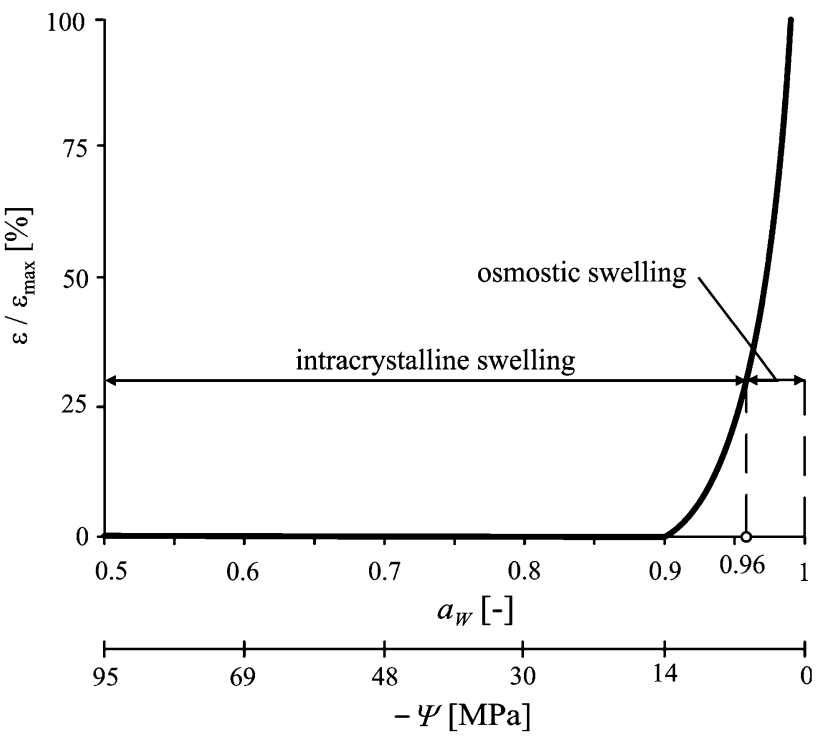

Fig. 8 Swelling strain (normalised by its final value) as a function of water activity (according to Mering 1946)

strain schematically (normalised by its final value) as a function of water activity. Mering (1946) noticed that up to a water activity $\alpha_{W}$ of 0.90 , i.e. in the range of extremely high negative values for the pore water potential $\Psi$, the volume of the particles increases significantly due to water absorption, but this occurs at the expense of the pore space and does not manifest itself in a macroscopic swelling. In the next stage $\left(0.9<\alpha_{W}<0.96\right)$, the distance of the clay platelets slightly increases, resulting in clay swelling, which is nevertheless relatively moderate. About $30 \%$ of the total swelling strain occurs in this intracrystalline phase (Fig. 8). The largest portion of the swelling strain occurs in the last (osmotic) stage, when the water activity rises above 0.96 ( $c f$. also Norrish and Quirk 1954; Devineau et al. 2006; Boidin et al. 2009; Bihannic et al. 2009).

As changes in the total potential $\Psi+p_{W}$ during intracrystalline swelling at very low water activities do not result in relevant strain, a possible interpretation of the behaviour in Fig. 8 is that these changes are not effective in the sense of Terzaghi, i.e. that they do not produce strains to the same extent that a change in the total stress $\sigma$ does. This can be expressed mathematically by taking the effective stress equal to $\sigma^{\prime}=\sigma-b\left(\Psi+p_{W}\right)$, where the coefficient $b$, which governs how effective a change of the total potential $\Psi+p_{W}$ is with respect to strain development, would be close to unity at high activities and close to zero at very high negative values for the pore water potential $\Psi$. In this case, the maximum swelling pressure would be equal to $\sigma_{s}=\sigma_{0}-b\left(\Psi_{0}+p_{W 0}\right)$, which means that the swelling pressure is considerably smaller than $-\Psi_{0}$.

A second possible interpretation of the behaviour in Fig. 8 is that the principle of effective stress is valid in its 
classic form [i.e. $\sigma^{\prime}=\sigma-\left(\Psi+p_{W}\right)$ ], but the dependency of strain on effective stress is highly nonlinear, characterised by an extremely high stiffness under the high compressive effective stresses that prevail at low water activities. (Note that, according to Fig. 8, a change in the water activity from 0.70 to 0.90 does not result in relevant strain despite the large change in effective stress of $\Delta \sigma^{\prime} \cong-\Delta \Psi=34 \mathrm{MPa}$.) In this case too, the measured swelling pressure would be considerably smaller than $-\Psi_{0}$, because the common oedometric devices unavoidably allow some strain to occur due to the combined effect of their finite stiffness and positioning of the dial gauges ( $c f$. Anagnostou 1991).

The authors believe that the first interpretation is more convincing, because it also has a theoretical basis: Coussy et al. (1999) formulated a poro-mechanical model with a non-constant coefficient $b$ which accounts for the interactions between the clay platelets according to the electric double-layer theory. They showed that the stronger these interactions are (i.e. the lower the water activity $\alpha_{W}$ ), the lower will be the value of $b$ and consequently the more pronounced will be the deviation from Terzaghi's original principle of effective stress; for an ideal pore solution (i.e. for $\left.\alpha_{W}=1\right) b=1$, while for non-ideal solutions (i.e. for $\left.\alpha_{W}<1\right) b<1$.

However, independently of which interpretation of the behaviour in Fig. 8 is true (i.e. deviation from Terzaghi's principle of effective stress vs. a highly nonlinear effective stress-strain relationship), both interpretations lead-for different reasons-to the same conclusion: the occurrence of very high negative $\Psi_{0}$ values in situ, which is a prerequisite for the low water activity hypothesis, is not contradicted by the fact that the swelling pressures measured in the claystones are relatively moderate.

\section{Conclusions}

We attempted to explain the occurrence of anhydrite in Gypsum Keuper at small depths prior to tunnel excavation (Fig. 2). Three effects were investigated quantitatively: the size of the pores; the local stresses generated due to gypsum growth in the pores; and the thermodynamic state of water in the presence of the clay phase.

Concerning the role of the pore size of anhydritic claystones, MIP experiments were performed on samples from the Gypsum Keuper (Sect. 2). Natural anhydritic rocks were found to contain not only extremely small pores, where anhydrite would be stable and gypsum growth is thermodynamically impossible, but also larger pores, where gypsum would precipitate, thus sustaining a process of anhydrite dissolution and ionic diffusion from the small pores to the large pores (Fig. 4). The consequence would be a complete transformation of anhydrite into gypsum. The so-called "small-pore hypothesis" must therefore be abandoned as it does not provide a general and robust explanation for the occurrence of anhydrite under the in situ conditions.

The hypothesis of high local stresses, initially proposed in relation to the Gypsum Keuper formation by Wichter (1989), has also proved deficient, except for the exceptional situation of extremely fine-porous rocks with uniform, regularly distributed pores (Sect. 3; Fig. 5). In general, the stress developing locally does not reach the level in all pores, which is thermodynamically required for the anhydrite to be stable (Fig. 6). This too would cause a complete transformation of anhydrite to gypsum via dissolution and diffusion.

The low activity hypothesis, which emphasises, following Lippmann and Schüle (1975), the role of the clay minerals with respect to the thermodynamic state of the pore water, provides the most convincing explanation for the occurrence of anhydrite at shallow depths (Sect. 4). Even if an experimental confirmation has yet to be made specifically for the anhydritic claystones of the Gypsum Keuper, the low water activity hypothesis does not make any unrealistic assumptions. In addition, it provides a consistent explanation of the processes taking place when anhydritic claystones come into contact with water: Swelling starts with water uptake by the clay minerals. During this first phase, the pore water activity gradually increases, reaching at some time point the gypsum-anhydrite equilibrium activity (Eq. 4). From this time point on, anhydrite to gypsum transformation takes place, consuming water and thus maintaining the water deficiency of the clay and sustaining the water uptake until all of the anhydrite is transformed into gypsum. At the end of the swelling process, the water activity becomes equal to 1 (fully swollen state of the clay).

Acknowledgments This paper evolved within the framework of the research project "Modelling of anhydritic swelling claystones", which is being carried out at the ETH Zurich with the financing of the Swiss National Science Foundation (SNF) under Project Nr. 200021-126717/1 and the Swiss Federal Roads Office (FEDRO) under Project Nr. FGU 2010-007. The authors would like to thank Prof. Robert Flatt, ETH Zurich, for his valuable suggestions concerning the importance of pore size and liquid-crystal interfacial effects; Dr. Andreas Leemann and Dr. Mateusz Wyrzykowski from EMPA, as well as Mrs Annette Röthlisberger from our Institute's Clay Mineralogy Lab for performing the MIP tests.

\section{Appendix}

Sections 2, 3 and 4 make frequent use of the following expressions for the equilibrium concentrations $c_{e q, G}$ and $c_{e q, A}$ of gypsum and anhydrite: 


$$
\begin{aligned}
R T \ln \left(\gamma_{ \pm} \frac{c_{e q, G}}{c_{0}} a_{W}\right)^{2}= & -\Delta_{r, G} G^{0}+\left(T-T_{0}\right) \Delta_{r, G} S^{0} \\
& +\left(p_{G}+\frac{2 \gamma_{G}}{r_{G}}\right) V_{G}^{0} \\
& -p_{W}\left(V_{G}^{0}+\Delta_{r, G} V^{0}\right),
\end{aligned}
$$

$$
\begin{aligned}
R T \ln \left(\gamma_{ \pm} \frac{c_{e q, A}}{c_{0}}\right)^{2}= & -\Delta_{r, A} G^{0}+\left(T-T_{0}\right) \Delta_{r, A} S^{0} \\
& +\left(p_{A}+\frac{2 \gamma_{A}}{r_{A}}\right) V_{A}^{0} \\
& -p_{W}\left(V_{A}^{0}+\Delta_{r, A} V^{0}\right)
\end{aligned}
$$

where $T, p_{G}, p_{A}$ and $p_{W}$ denote the temperature, the gypsum pressure, the anhydrite pressure and the pore water pressure, respectively. The symbols $\gamma_{G}, r_{G}, \gamma_{A}$ and $r_{A}$ denote the surface energies and the particle radii of gypsum and anhydrite. The surface energy $\gamma_{G}$ of gypsum can be taken equal to $80 \mathrm{mN} / \mathrm{m}$, while the effect of surface energy of the anhydrite particles (term $2 \gamma_{A} / r_{A}$ ) can be neglected because of their relatively large size $(>1 \mu \mathrm{m})$. The symbol $\gamma_{ \pm}$ denotes the mean activity coefficient of the dissolved ions and can be computed after Davies (1962). The symbols $c_{0}$ and $T_{0}$ denote the standard concentration $(1 \mathrm{~mol} / \mathrm{l})$ and the standard temperature $(298 \mathrm{~K})$, respectively. The other symbols appearing in Eqs. (6) and (7) are the thermodynamic constants. More details, including the derivations of the equations as well as the values of the thermodynamic constants, can be found in Serafeimidis and Anagnostou (2014).

\section{References}

Abell BA, Willis LK, Lange AD (1999) Mercury Intrusion Porosimetry and Image Analysis of Cement-Based Materials. J Colloid Interface Sci 211(1):39-44

Alonso EE, Olivella S (2008) Modelling tunnel performance in expansive gypsum claystones. In: International Association for Computer Methods and Advances in Geomechanics (IACMAG), Goa, India, pp 891-910

Amstad C, Kovári K (2001) Untertagbau in quellfähigem Fels. Schlussbericht Forschungsauftrag 52/94 des Bundesamts für Strassen, ASTRA

Anagnostou G (1991) Untersuchungen zur Statik des Tunnelbaus in quellfähigem Gebirge. Dissertation Nr. 9553, ETH Zürich

Anagnostou G (1993) A model for swelling rock in tunnelling. Rock Mech Rock Eng 26(4):307-331

Anagnostou G, Kovári K (1993) Significant parameters in elastoplastic analysis of underground openings. J Geotech Eng 119(3):401-419

Bihannic I, Delville A, Demé B, Plazanet M, Villièras F, Michot LJ (2009) Clay swelling: New insights from Neutron-Based Techniques. In: Liang L, Rinaldi R, Schober H (eds) Neutron Applications in Earth. Springer, Energy and Environmental Sciences, pp 521-546

Boidin E, Homand F, Thomas F, Yvon J (2009) Anhydrite-gypsum transition in the argillites of flooded salt workings in eastern France. Environ Geol 58:531-542
Chiaverio F, Thut A (2010) Chienberg Tunnel Rehabilitation using yielding elements of the section in Keuper sediments affected by heave. Geomech Tunn 3(5):573-582

Coussy O, Dangla P, Dormieux L, Lemarchand E (1999) A two-scale modelling of a swelling clay. J Phys IV France 9:21-31

Dassault Systèmes (2011) Abaqus 6.11-Theory Manual and Analysis User's Manual

Davies CW (1962) Ion association. Butterwoths, London

Devineau K, Bihannic I, Michot L, Villiéras F, Masrouri F, Cuisinier O, Fragneto G, Michau N (2006) In situ neutron diffraction analysis of the influence of geometric confinement on crystalline swelling of montmorillonite. Appl Clay Sci 31:76-84

Fecker E (1981) Influence of swelling rock on tunnelling. Bull Int Assoc Eng Geol 24:27-32

Flatt JR (2002) Salt damage in porous materials: how high supersaturations are generated. J Cryst Growth 242:435-454

Grob H (1972) Schwelldruck im Belchentunnel. In: Proceedings of the International Symposium on Underground Construction, Lucerne, Switzerland, pp 99-119

Hauber L, Jordan P, Madsen F, Nüesch R, Vögtli B (2005) Tonminerale und Sulfate als Ursache für druckhaftes Verhalten von Gesteinen-Ursachen und Wirkungen des Quellvorganges. Forschungsauftrag ASTRA 1996/039

ISRM (1999) Suggested methods for laboratory testing of swelling rock. Int J Rock Mech Min Sci 36:291-306

Jordan P (1994) Evaporite als Abscherhorizonte-Eine gefügekundlich-strukturgeologische Untersuchung am Beispiel der Nordschweizer Trias. Beiträge zur geologischen Karte der Schweiz, Lieferung, p 164

Krause H (1976) Sulphate rocks in Baden-Württemberg and their importance in relation to civil engineering. Bull Int Assoc Eng Geol 13:45-49

Krause H, Wurm F (1975) Geologische Grundlagen und Untersuchungen zum Problem der Sohlhebungen in Keupertunneln BadenWürttembergs. In: Durchführung eines felsmechanischen Grossversuches in der Nordröhre des Wagenburgtunnels in Stuttgart. Hrsg. Bundesminister f. Verkehr, Bau- und Wohnungswesen. Strassenbau und Strassenverkehrstechnik, Heft 184:9-41

Kuhnhenn K, Lorscheider W (1979) Sondierstollen mit Probestrecken für den Engelberg-Basistunnel der Autobahn Heilbronn-Stuttgart. Rock Mech, Suppl. 8:147-171

Leemann A, Wyrzykowski M (2012) MIP tests on Gypsum Keuper samples from the Chienberg and Belchen Tunnel. Internal laboratory test report, EMPA

Lippmann F (1976) Corrensite, a swelling clay mineral, and its influence on floor heave in tunnels in the Keuper formation. Bull Int Assoc Eng Geol 13:65-70

Lippmann F, Schüle F (1975) Mineralogische Untersuchungen an Keupergesteinen unter besonderer Berücksichtigung der Tonminerale. In: Durchführung eines felsmechanischen Grossversuches in der Nordröhre des Wagenburgtunnels in Stuttgart. Hrsg. Bundesminister $\mathrm{f}$. Verkehr, Bau- und Wohnungswesen. Strassenbau und Strassenverkehrstechnik, Heft 184, pp 119-148

Mering J (1946) On the hydration of montmorillonite. Trans Faraday Soc 42:205-219

Mitaritonna G, Pineda J, Arroyo M, Romero E (2009) The effect of drying-wetting cycles on the seismic properties of an anisotropic claystone. In: Ling HI, Smyth A, Betti R (eds) Biot conference on poromechanics, vol 4. DEStech Publications Inc, PA, pp 286-293

Mohajerani M, Delage P, Monfared M, Tang AM, Sulem J, Gatmiri B (2012) On the resaturation of swelling claystone. In: Mancuso C, Jommi C, D’Onza F (eds) Unsaturated soils: research and applications, Springer, Berlin, pp 411-417

Norrish K, Quirk JP (1954) Crystalline swelling of montmorilloniteuse of electrolytes to control swelling. Nature 173:255-256 
Oldecop L, Alonso E (2012) Modelling the degradation and swelling of clayey rocks bearing calcium-sulphate. Int J Rock Mech Min Sci 54:90-102

Paul A, Wichter L (1996) Das Langzeitverhalten von Tunnelbauwerken im quellenden Gebirge-Neuere Messergebnisse vom Stuttgarter Wagenburgtunnel. Taschenbuch für den Tunnelbau, Verlag, pp 135-164

Pimentel E (2007) Quellverhalten von Gesteinen-Erkenntisse aus Laboruntersuchungen. Quellprobleme in der Geotechnik, Mitteilungen der Schweizerischen Gesellschaft für Boden- und Felsmechanik, Frühjahrstagung Freiburg 154:11-20

Prommersberger G, Kuhnhenn K (1989) The Freudenstein tunneltunnel construction in swelling rocks. Rapid Excavation and Tunneling Conference Los Angeles, California, Chapter 42, June 11-14, pp 678-700

Rauh F (2009) Untersuchungen zum Quellverhalten von Anhydrit und Tongesteinen im Tunnelbau. Müncher Geowissenschaftliche Abhandlungen 11:1-110

Rolnick SL (1954) The stability of gypsum and anhydrite in the geologic environment. PhD Thesis, Massachusetts Institute of Technology

Röthlisberger A (2012) MIP tests on Gypsum Keuper samples from the Chienberg and Belchen Tunnel. Internal laboratory test report, Institute for Geotechnical Engineering, ETH Zurich
Scanlon RB, Andraski JB, Bilskie J (2002) Miscellaneous methods for measuring matric or water potential. In: Dane JH, Topp GC (eds) Methods of soil analysis, part 4: physical methods. Soil Science Society of America, Madison, pp 643-670

Scherer WG (2002) Factors affecting crystallization pressure. In: International RILEM TC 186-ISA Workshop on Internal Sulfate Attack and Delayed Ettringite Formation, Villars, Switzerland, pp 139-154

Scherer WG (2004) Stress from crystallization of salt. Cem Concr Res 34:1613-1624

Serafeimidis K, Anagnostou G (2013) On the time-development of sulphate hydration in anhydritic swelling rocks. Rock Mech Rock Eng 46:619-634

Serafeimidis K, Anagnostou G (2014) The solubilities and thermodynamic equilibrium of anhydrite and gypsum. Rock Mech Rock Eng. doi:10.1007/s00603-014-0557-1

Wichter L (1989) Quellen anhydrithaltiger Tongesteine. Bautechnik 66(1):1-6

Woodburn JA, Holden JC, Peter P (1993) The transistor psychrometer: a new instrument for measuring soil suction. In: Houston SL, Wray WK (eds) Unsaturated soils, vol 39. Geotechnical Special Publication, New York, pp 91-102

Zhang F, Xie SY, Hu DW, Shao JF, Gatmiri B (2012) Effect of water content and structural anisotropy on mechanical property of claystone. Appl Clay Sci 69:79-86 